\title{
New Faiths, Old Fears: Muslims and Other Asian Immigrants in American Religious Life
}

\author{
Bruce B. Lawrence \\ New York: Columbia University Press, 2002. 197 pages.
}

Bruce Lawrence's book, New Faiths, Old Fears: Muslims and Other Asian Immigrants in American Religious Life, seeks to remedy theoretical gaps by correcting the emphasis on East Asians within Asian-American studies and by describing Asian Americans in relation to other minorities and dominant Anglos within the prevailing ethno-racial system (p. xiv). As a religious studies scholar with "a lifelong engagement with Islam, and an exuberant attachment to South Asia" (p. 38), he discusses post-1965 immigration and underscores its religious and cultural dimensions. The range of controversial topics broached in this book promise to appeal to a broad readership. Topics covered include historical and politico-economic aspects of immi- 
gration, racial prejudice, cultural and religious fundamentalism, arguments over multiculturalism, transnational identities, and media representations of religion. Consequently, New Faiths, Old Fears is highly significant for those interested in religious studies, sociology, anthropology, history, and cultural studies - and especially for those interested in immigration and Asian Americans.

This book is divided into an introduction, five chapters, and a conclusion. In the "Introduction," Lawrence describes disciplinary perspectives and immigration following policy changes in 1965 that especially benefited Latinos and Asians. He argues that like other immigrations, studies of AsianAmerican immigration must choose between four levels of discourse: public policy, law, cultural studies, and that of the participants themselves. Adopting a "culturalist" perspective, Lawrence stresses religion as a significant dimension of immigrant identity and struggle within American space (p. 8) and "race as a variable crucial to religion" (p. 2). Asian Americans are challenged to understand their location in the bipolar racialized pattern of American society despite the post-1970 emergence of the ethno-racial pentagon consisting of the overarching categories of Asians, Hispanics, Native Americans, Blacks, and Whites.

The author introduces three key terms that are used throughout the book: polyvalence, kaleidoculture, and racialized class prejudice. Polyvalence is "perpetual variety and change ... stability and persistence ... negotiated equivalence without guaranteed permanence" (p. 9). Kaleidoculture, derived from the metaphor of a kaleidoscope, is "the alternative to multiculturalism" that "evokes a changing spectrum of cultural values and experiences" (p. 9). Combining these terms forms a polyvalent kaleidoculture, which Lawrence projects as a hopeful outcome of American society's increasing diversity.

However, his third term, racialized class prejudice, presents the major obstacle to realizing this ideal. This critical concept combines studies of whiteness with the idea of "class prejudice," which "underscores how the economic and social and cultural resources of whiteness are denied to all non-whites, but especially to one race that is underlined as occupying the other end of an unspoken U.S. hierarchical social order, namely, African Americans" (p. 10). Although his focus on racialized constructions and hierarchies is an important contribution, since it relates Asian-American and other immigrants to the broader relational system, I remained unconvinced throughout most of the book that this term is more accurate than mere racial prejudice. 
Chapter 1, "American Religion as Commodity Culture," contrasts the perspectives of Diana Eck and Samuel Huntington toward multiculturalism. Lawrence demonstrates that although they have opposing positions, they share global and timeless conceptions of culture and religion. In contrast, he argues for a different conception of culture and religion based in particular historical and social contexts that project the polyvalent kaleidoscope into the future, rather than hegemonic multiculturalism or assimilation.

In chapter 2, "Civil Society and Immigrants," he relates narratives of Muslim and Hindu immigrants to productions of civil society. The first narrative describes Asian Muslim activists using "orthodox" Islam as a means to construct a unified Muslim identity. They call on universal Islamic ideals while, in practice, the ummah is riddled with racialized class prejudice. The second narrative discusses a Hindu organization (the Vishwa Hindu Parishad) that promotes political activism in the United States and in India by emphasizing endogamy and Hindu nationalism via temple restoration. Neither these groups nor the American Patriotic Protestants present a pristine image of tolerant civic associations. Nevertheless, Lawrence notes that it is essential to maintain a distance between church and state in the postSeptember 11 environment (p. 67).

The author also discusses the possibilities of creating a transnational civil society in cyberspace, noting that access to global network connectivity is not distributed equally. While highly educated urban professionals located in global cities may revel in "cyber fantasies," menial, semiskilled, and service-sector workers experience "global obscenities" (p. 63). Similarly, in chapter 4, "Religious Options for Urban Immigrants," he contrasts the urban spaces, Bank City and Shopping City, inhabited by middle- to upper-middleclass Iranian immigrants and lower-class Mexican immigrants, respectively. We may find racialized class prejudice reinscribed in cyberspace (p. 64). In chapter 5, "Reimagining Religious Pluralism," he notes the potential of the World Wide Web to "provide a fuller exposition of varieties of religious experience, and expression, for immigrants and others," compared to what print journals could ever portray (p. 132).

Lawrence addresses the popular and academic representations of immigrants in chapter 3, "New Immigrants as Pariahs," stressing the point that conservative Anglo elites controlled the 1980s rhetoric that singled out poor immigrants as detrimental to American society (p. 75). These dominant representations contrast with the realities of South Asian immigrants, who were largely educated professionals in the pre-1986 and post-1990 waves. He notes that "Asians," who were included with whites for most of the century, 
were given a separate census category after 1970. Yet for them, "Anglos remained the preferred upper class, Africans the marginalized underclass" (p. 83). Here, his key term racialized class prejudice appears most appropriate in referring to the imaginations and biased preferences of many Asian immigrants; whereas simply racial stratification and prejudice may be more accurate in most other instances.

Nevertheless, the consistent concern Lawrence shows for the way race and religion are intertwined, both in the Anglo-Protestant slant of American civil religion as well as in the preferences of practitioners of new faiths, is a major contribution of this book. In addition, the author's insights into the varied orientations of South and West Asian immigrants, from "long-distance nationalism" to assimilation, are important and useful. As a whole, this book not only fills in some key theoretical gaps, but also offers new and hopeful models for conceiving of American diversity.

Timothy P. Daniels Assistant Professor of Anthropology Hofstra University, Hempstead, New York 